\title{
Reconstruction of Conifer Root Systems Mapped with Point Cloud Data Obtained by 3D Laser Scanning Compared with Manual Measurement
}

\author{
Chikage Todo ${ }^{1,2, *}$, Hidetoshi Ikeno ${ }^{3}\left(\mathbb{D}\right.$, Keitaro Yamase ${ }^{1}$, Toko Tanikawa ${ }^{4}$, Mizue Ohashi ${ }^{5}$, Masako Dannoura ${ }^{6}$, \\ Toshifumi Kimura ${ }^{5}$ and Yasuhiro Hirano ${ }^{2}$ (D)
}

check for

updates

Citation: Todo, C.; Ikeno, H.;

Yamase, K.; Tanikawa, T.; Ohashi, M.;

Dannoura, M.; Kimura, T.; Hirano, Y.

Reconstruction of Conifer Root

Systems Mapped with Point Cloud

Data Obtained by 3D Laser Scanning

Compared with Manual

Measurement. Forests 2021, 12, 1117.

http:/ / doi.org/10.3390/f12081117

Academic Editor:

Antonio Montagnoli

Received: 14 July 2021

Accepted: 18 August 2021

Published: 21 August 2021

Publisher's Note: MDPI stays neutral with regard to jurisdictional claims in published maps and institutional affiliations.

Copyright: (c) 2021 by the authors. Licensee MDPI, Basel, Switzerland. This article is an open access article distributed under the terms and conditions of the Creative Commons Attribution (CC BY) license (https:/ / creativecommons.org/licenses/by/ $4.0 /)$.
1 Hyogo Prefectural Technology Center for Agriculture, Forestry and Fisheries, Shiso 671-2515, Japan; kei-yamase@nike.eonet.ne.jp

2 Graduate School of Environmental Studies, Nagoya University, Nagoya 464-8601, Japan; yhirano@nagoya-u.jp

3 Faculty of Informatics, The University of Fukuchiyama, Fukuchiyama 620-0886, Japan; ikeno-hidetoshi@fukuchiyama.ac.jp

4 Graduate School of Bioagricultural Sciences, Nagoya University, Nagoya 464-8601, Japan; toko105@agr.nagoya-u.ac.jp

5 School of Human Science and Environment, University of Hyogo, Himeji 670-0092, Japan; ohashi@shse.u-hyogo.ac.jp (M.O.); kimura@shse.u-hyogo.ac.jp (T.K.)

6 Graduate School of Agriculture, Kyoto University, Kyoto 606-8502, Japan; dannoura.masako.4w@kyoto-u.ac.jp

* Correspondence: chikage_toudou@pref.hyogo.lg.jp

\begin{abstract}
Three-dimensional (3D) root system architecture (RSA) is a predominant factor in anchorage failure in trees. Only a few studies have used 3D laser scanners to evaluate RSA, but they do not check the accuracy of measurements. 3D laser scanners can quickly obtain RSA data, but the data are collected as a point cloud with a large number of points representing surfaces. The point cloud data must be converted into a set of interconnected axes and segments to compute the root system traits. The purposes of this study were: (i) to propose a new method for easily obtaining root point data as 3D coordinates and root diameters from point cloud data acquired by 3D laser scanner measurement; and (ii) to compare the accuracy of the data from main roots with intensive manual measurement. We scanned the excavated root systems of two Pinus thunbergii Parl. trees using a 3D laser scanner and neuTube software, which was developed for reconstructing the neuronal structure, to convert the point cloud data into root point data for reconstructing RSA. The reconstruction and traits of the RSA calculated from point cloud data were similar in accuracy to intensive manual measurements. Roots larger than $7 \mathrm{~mm}$ in diameter were accurately measured by the 3D laser scanner measurement. In the proposed method, the root point data were connected as a frustum of cones, so the reconstructed RSAs were simpler than the 3D root surfaces. However, the frustum of cones still showed the main coarse root segments correctly. We concluded that the proposed method could be applied to reconstruct the RSA and calculate traits using point cloud data of the root system, on the condition that it was possible to model both the stump and ovality of root sections.
\end{abstract}

Keywords: anchorage; coarse root; measurement method; Pinus thunbergii; root cross-sectional area; root system architecture

\section{Introduction}

Root systems anchor trees, capture and store resources, and sense the environment [1]. They contribute to the resistance to uprooting and prevent soil erosion, thus supporting slope stability $[2,3]$.

Three-dimensional (3D) root system architecture (RSA) is a predominant factor in anchorage failure [4-8]. Root system traits that can be obtained from RSA include: the 
total root cross-sectional area (CSA) in a cross-section parallel to the slope [9], the pullout resistance of roots as calculated from root diameter [10], and root volume in the root compartments such as tap root or horizontal roots [11]. Danjon et al. [7] reviewed the relationships between the RSA and anchorage and indicated the importance of compartment classification of RSA with different root system types by architectural analysis. Root systems must be excavated for such investigations, and given their size; it is necessary to obtain data efficiently.

The RSA of forest trees [12] is often calculated from 3D point data with root connections determined from $x y z$ coordinates (ground surface position and depth) and diameter. Danjon and Reubens [12] reviewed and categorized methods for acquiring 3D root point data into manual, semi-automatic, and automatic methods. The manual measurement was the simplest but was labor and time-intensive [12,13]. Henderson et al. [14] determined the $x$ and $y$ coordinates by moving a T-square on an aluminum frame and the $z$ coordinate by lowering a plumb bob and obtained data on the RSA of Picea sitchensis (Bong.) Carr. with a stem diameter at a breast height (DBH) of 9.0-11.5 cm. Mulatya et al. [15] obtained data on RSA by creating a level grid around Melia volkensii Gürke to measure coordinates where the branching and angles of the root system changed. Semi-automatic methods included the measurement of 3D root point data using a digital compass and an inclinometer [16] or a contact digitizer, and AMAPmod software with MTG coding [17-19]. Saint Cast et al. [20] used semi-automatic methods to obtain RSA data of Pinus pinaster Ait. from the seed to the mature stage and modeled the 3D structure of the entire root system. The method of using a 3D digitizer and yielding MTG format files was used extensively because it provided a precise 3D database of root architecture as a set of axes and segments [12], allowing the computation of many root traits. In addition, classifying segments in several root compartments, such as the zone of rapid taper (ZRT), has become the mainstream of RSA data analysis in recent years [12].

On the other hand, automatic methods that can obtain data on RSA rapidly collect data as a point cloud that consists of a very large number of points representing the root surfaces. Lontoc-Roy et al. [21] used computed tomography to obtain point cloud data of the root systems of tree seedlings, but this method cannot be used on large trees in the field. Additionally, the method did not convert point cloud data to root axes and segments. An automatic method that can be applied to large trees uses three-dimensional (3D) laser scanners. Although 3D laser scanners are expensive, they can collect point cloud data from 3D surfaces with high accuracy without contact, and thus, are used for measuring the aboveground parts of trees [22-26]. Lau et al. [27] reported the accuracy of the traits of branches $>10 \mathrm{~cm}$ in diameter reconstructed from the 3D quantitative structure models (QSM) from point cloud data using a 3D laser scanner in 4, up to $30 \mathrm{~m}$ high, tropical tree species with the leaves, scanned from the ground. However, only large branches ( $>40 \mathrm{~cm}$ in diameter) could be accurately reconstructed compared to manual measurements. Gärtner et al. [28] used 3D laser scanning to acquire point cloud data of the entire root system of 80-year-old Picea abies (L.) Karst. trees. Wagner et al. [29,30] created annual growth models at the root segments from 3D laser scans of the root system and 2D annual tree-ring data of 12-year-old Pinus sylvestris L. The mean absolute percentage error per volume of two root segments with diameters of $1.6 \mathrm{~cm}$ and $1.8 \mathrm{~cm}$ was reported to be $6.0 \%$ on average. Smith et al. [31] measured the volumes of 13 root systems of P. abies trees with a $19-47 \mathrm{~cm}$ stump diameter by converting point cloud data into polygon data using computer-aided design software. Only a few studies have used 3D laser scanning to evaluate root systems [12]. The 3D QSM reconstruction method has been used for both above- and below-ground of trees, but it requires specific parameters to fit the model, which could vary the accuracy of reconstruction [27,31]. Although only a theoretical comparison between semi-automatic methods and 3D laser scanning was reported in Danjon and Reubens [12], the accuracy of root point data reconstructed from 3D laser scan measurement has never been checked [31]. Moreover, 3D laser scanning has yet to be fully used for measuring the root system traits such as diameter and CSA from point cloud data. 
Although it is the best available technique to describe the shapes of root surfaces, intensive intervention is still required for calculating root system traits [12]. Therefore, an automated step is needed to convert the point cloud data of the root surface measured by a 3D laser scanner to the root point data.

The purposes of this study were: (i) to propose a new method for easily obtaining root point data as 3D coordinates and root diameter from point cloud data acquired by a 3D laser scanner; and (ii) to compare the accuracy of the root point data with that collected by intensive manual measurement.

Interrelated root segments with just a base and an end diameter will be hereafter referred to as 'segments'. Interrelated root points, each with a diameter, forming axes, and segments, will be referred to as 'root point data'.

This study focused on Pinus thunbergii Parl., which is the main plantation in Japanese coastal forests. The excavated root systems of $P$. thunbergii were scanned using a 3D laser scanner, and the point cloud data were converted to root point data, from which we reconstructed the RSA data. Root point data were also acquired manually. We compared the RSA data obtained by the two methods and examined the reproducibility of both datasets from the root CSA.

\section{Material and Methods}

\subsection{Test Trees}

Root systems of Pinus thunbergii Parl. trees were targeted (root system 1, root system 2) as shown in Figure 1. The trees grew in a coastal forest stretching $8 \mathrm{~km}$ to the west end of the Atsumi Peninsula, Tahara City, Aichi, Tokai District, Japan [32-35], and were replanted after heavy damage by Typhoon Vera in 1959 [32]. The soil was sandy in nature [36]. From 1981 to 2010 , the mean annual temperature was $16.0^{\circ} \mathrm{C}$, and the mean annual precipitation was $1603 \mathrm{~mm}$ [37].
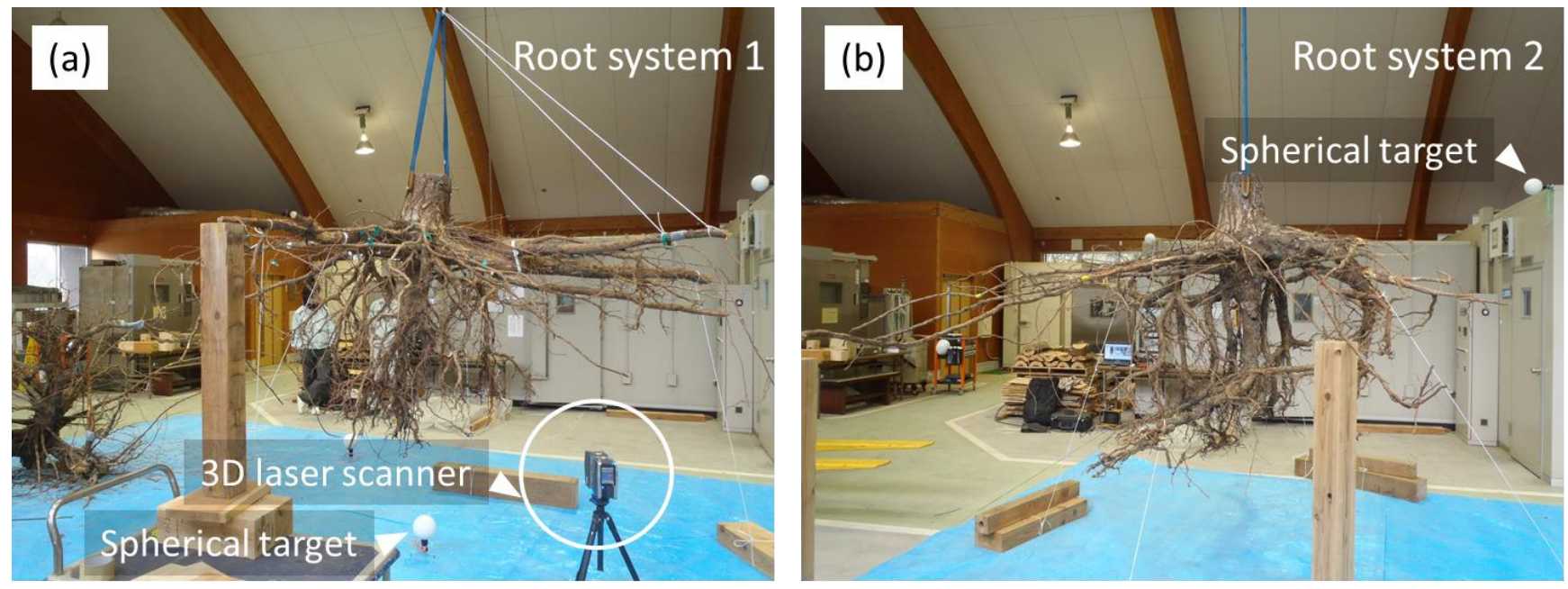

Figure 1. Measurement of (a) Root system 1, (b) Root system 2 by 3D laser scanner.

After measuring the tree height and $\mathrm{DBH}$, we measured the critical turning moment in tree-pulling experiments using the method described by Todo et al. [35] and cut the trees at the ground level. The tree-pulling experiment was performed as follows: a polyester belt sling (safe working load: $6.3 \mathrm{t}$ ) was attached to the tree, connected to a $10 \mathrm{~mm}$ diameter wire rope $1 \mathrm{~m}$ above the ground, and this was pulled, parallel to the ground, by an excavator. A load cell (maximum load 50 kN, LT-50KNG56 NIKKEI Electronic Instruments Co. Ltd., Tokyo, Japan) was connected between the belt sling and wire rope, and the load data were recorded at intervals of $0.1 \mathrm{~s}$ through a bridge unit (DBU-120A, KYOWA Electronic Instruments Co. Ltd., Tokyo, Japan). Measurements of the loads for the tree-pulling experiments began before the excavator commenced pulling the wire rope and stopped 
when the load began to decrease after reaching the maximum. In this study, the test trees were not uprooted because the maximum critical turning moment has already reached before [35] and the root system could keep the positions in soils.

The trees were aged from the rings in the stump, and the whole root system was dug out using an air spade $[33,34]$ in January 2014 . The two trees were 45 and 50 years old, the DBHs were 19.5 and $18.5 \mathrm{~cm}$, and the heights were $10.8 \mathrm{~m}$ and $11.4 \mathrm{~m}$ (Table 1), respectively. The maximum root depth was $126 \mathrm{~cm}$ in root system 1 and $106 \mathrm{~cm}$ in root system 2 . Both trees had tap root systems (Figure 1). On the other hand, the critical turning moment in root system 2 was approximately 1.3 times that in root system 1, probably owing to different RSAs (Table 1). The excavated root systems were placed inside a room so as to preserve the 3D RSA.

Table 1. Properties of Pinus thunbergii trees.

\begin{tabular}{ccc}
\hline Properties & Root System 1 & Root System 2 \\
\hline Age $(\mathrm{y})$ & 45 & 50 \\
Height $(\mathrm{m})$ & 10.8 & 11.4 \\
Stem diameter at breast height $(\mathrm{cm})$ & 19.5 & 18.5 \\
Critical turning moment $(\mathrm{kN} \cdot \mathrm{m})$ & 25.5 & 33.6 \\
Maximum depth of root $(\mathrm{cm})$ & 126 & 106 \\
\hline
\end{tabular}

\subsection{D Laser Scanner Measurement}

Point cloud data on the surface of the root system (Figures 2-4) were collected using 3D laser scanners (FARO Focus3D S120, FARO Technologies Inc., Lake Mary, FL, USA) (Figure 1). The two root systems were suspended while facing up in a room and supported to maintain the original RSA. The suspended root system was positioned by keeping the ground surface portion of the stump horizontal and aligning it with the orientation of the site. The two root systems were individually scanned from eight positions using a 3D laser scanner (FARO S120) within $2 \mathrm{~m}$ from the center of the collar. Scanning was performed to cover the entire root system, and three spherical targets were identified in each scan. The scanner had a measurement range of $0.6 \mathrm{~m}$ to $120 \mathrm{~m}$ with a vertical field of view of $300^{\circ}$ and a horizontal field of view of $360^{\circ}$. The angular resolution was $0.009^{\circ}$ for both horizontal and vertical angles. The scanner output was a $905 \mathrm{~nm}$ laser beam with a $3 \mathrm{~mm}$ circular diameter and $0.19 \mathrm{mrad}$ divergence. The scanner had a stated error of $2 \mathrm{~mm}$ between the scanner position and the shooting object and a standard deviation in the optimum plane scan of $\leq 2 \mathrm{~mm}$ [38]. The point cloud data taken from each position were integrated into one $3 \mathrm{D}$ point cloud data by matching the reflected spherical targets. FARO Scene (FARO Technologies, Inc., version 5.1.6) was used to integrate the point cloud data. 


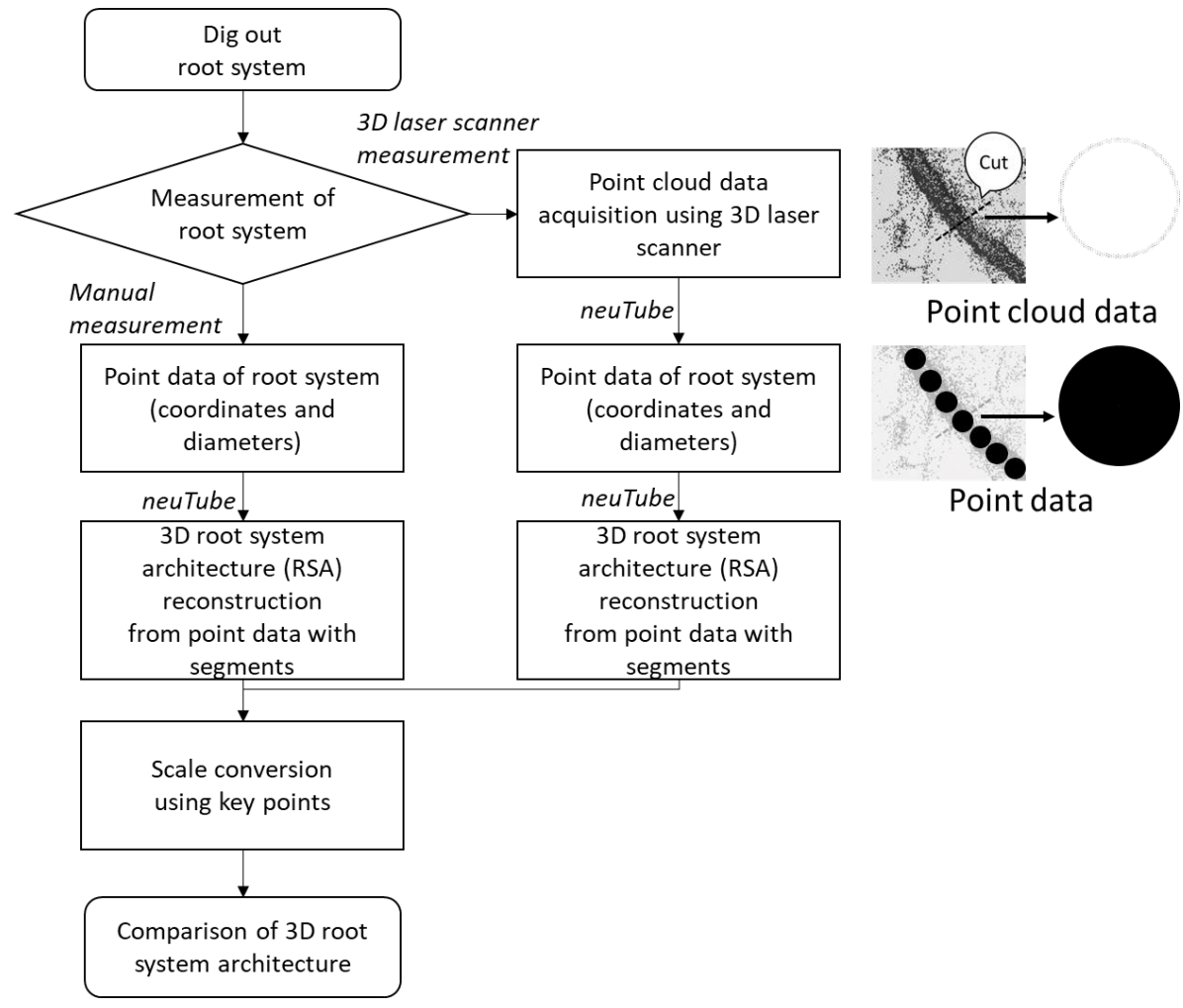

Figure 2. Acquisition of point cloud data and root point data and reconstruction of root system architecture (RSA).

\section{Root system 1}

$\stackrel{\text { Top view }}{\longleftrightarrow} \underset{\text { 3D laser scanner } \quad \text { Manual }}{\longrightarrow}$

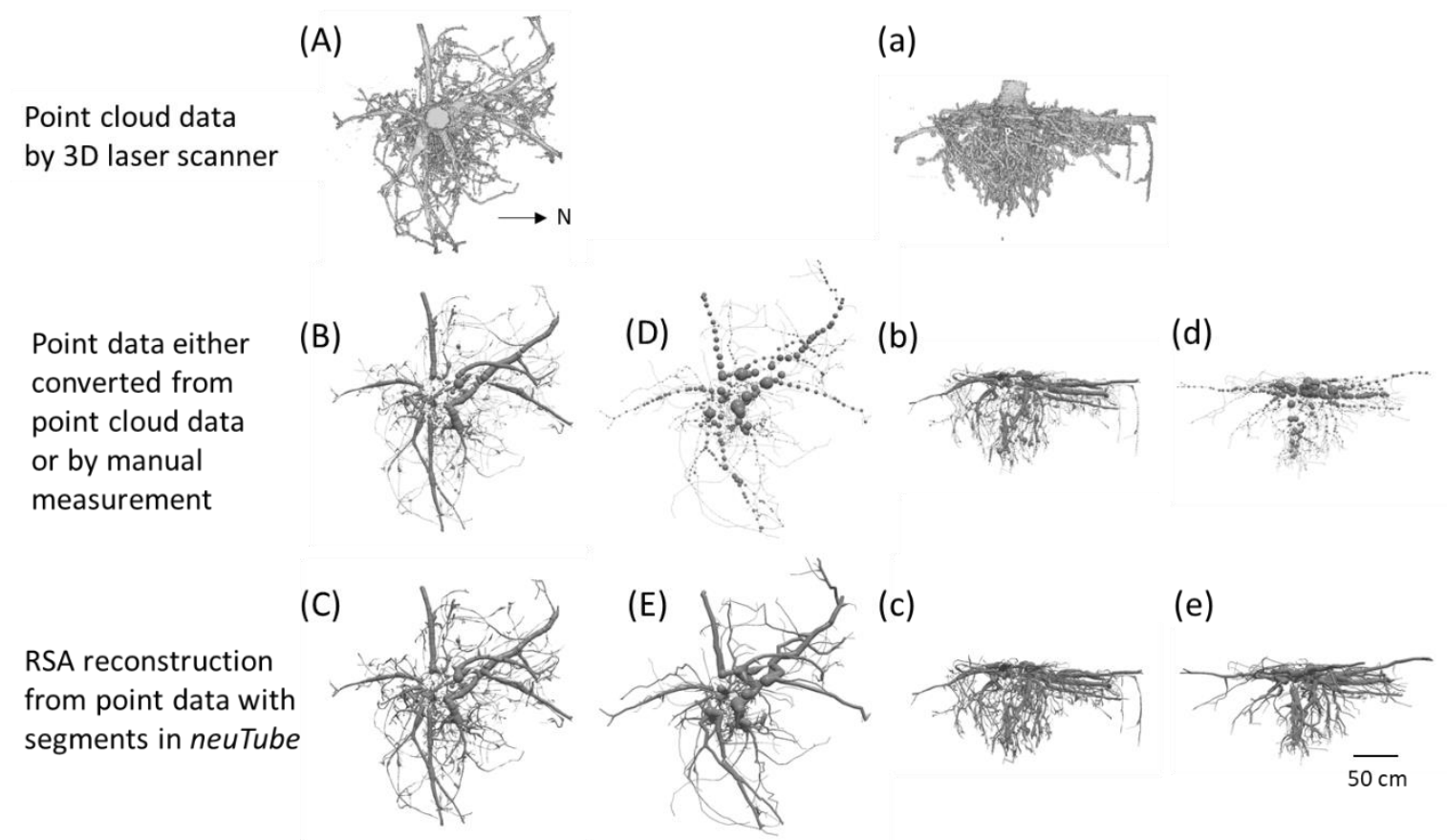

Figure 3. (A-E) Top and (a-e) side views of Root system 1 drawn from (A,a) point cloud data collected by 3D laser scanner; root point data; $(\mathbf{B}, \mathbf{b})$ converted from point cloud data; $(\mathbf{D}, \mathbf{d})$ gathered by hand; and $(\mathbf{C}, \mathbf{E}, \mathbf{c}, \mathbf{e})$ RSA reconstructed by neuTube software. 


\section{Root system 2}

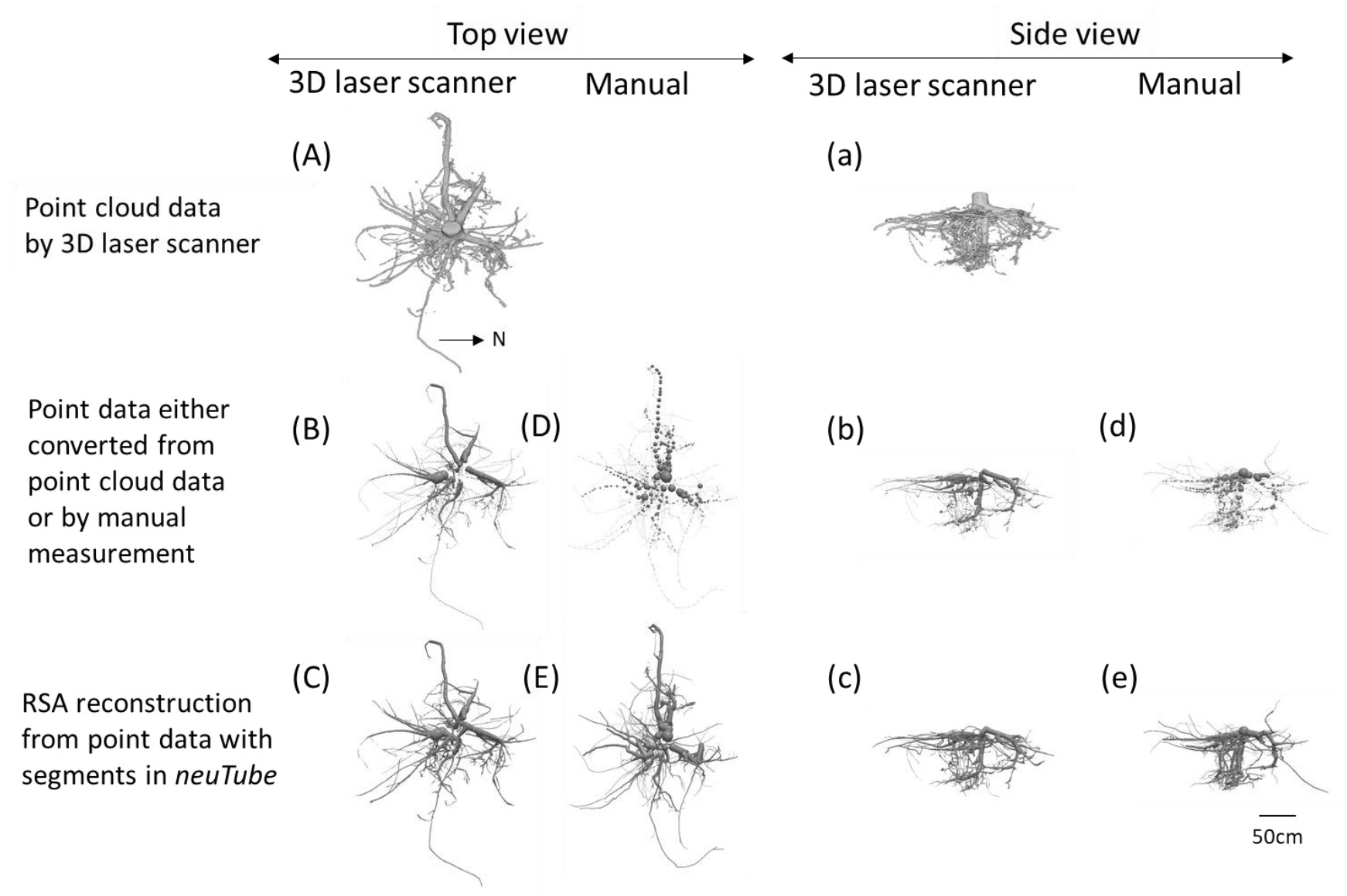

Figure 4. (A-E) Top and (a-e) side views of Root system 2 drawn from (A,a) point cloud data collected by 3D laser scanner root point data; $(\mathbf{B}, \mathbf{b})$ converted from point cloud data; $(\mathbf{D}, \mathbf{d})$ gathered by hand; and $(\mathbf{C}, \mathbf{E}, \mathbf{c}, \mathbf{e})$ RSA reconstructed by neuTube software.

We used free software designed for digital reconstruction of neuron morphologies, neuTube [39], to generate structural models of the roots from the image data. One method used to measure the morphology of neurons with complex branching structures is to obtain a series of images of fluorescently stained neurons while changing the focal plane (confocal microscopic images) and then reconstruct the 3D structure. As neuTube was developed to analyze the branching structure of neurons from confocal image data, we thought it may be useful in analyzing tree root system data.

First, we extracted the point cloud data from only the root surfaces by deleting other noise data using FARO Scene's scatter filter and then manually eliminating the remaining noise. Second, we stratified the point cloud data by depth and created a series of 2D cloud image data points every $1 \mathrm{~cm}$. As the point cloud data describe only the root surfaces, the outer periphery of the root CSA appears in each image. Third, the area enclosed by each circle along the long axis of each root segment was filled manually and visually using ImageJ software. Even in an unclosed circle such as straight horizontal roots, we could identify it and fill between unclosed parallel lines manually and visually. The series of sliced images were loaded into neuTube [39], and the automatic tracing function tracked each circle in the long axis direction, outputting data related to the diameter at the branch points and connections between roots, that is, the information of root point data. The number of root point data converted from the point cloud data in root systems 1 and 2 was 5885 and 2301, respectively. All these steps, including those involving neuTube, can be performed on a regular PC. The cross-section of each segment was assumed to be a circle in this software. In this study, we did not collect point data of the stumps from the 
point cloud data because we focused on the possibility of reconstruction of the root system, particularly the traits of the main roots and root segments.

\subsection{Manual Measurement}

The root point data were also acquired through manual measurements [13]. Each root system was fixed upside down over a sheet marked with a $100 \mathrm{~mm} \times 100 \mathrm{~mm}$ grid that served as a guide for the $x$ and $y$ coordinates (Figure S1). The horizontal level of the stump was maintained at the ground surface to adjust the root position, the $y$-axis direction was fixed to the north, and the flexible roots were fixed in stands while comparing the photos taken in the field to those during the 3D scan. Roots whose $z$ coordinates were displaced by being upside down were adjusted on a stand. After cutting off thin roots with a diameter of $<5 \mathrm{~mm}$, we measured the 3D coordinates $(x, y, z)$ and the diameter of roots at root end points, branch points, and where the grid lines intersected with the roots (Figure S1). Each root point was assigned an ID number, and the connections between the points were recorded. The horizontal coordinates $(x, y)$ were measured with a steel tape with reference to the grid lines, and the $x$ and $y$ coordinates were determined using the center of the root collar as the origin. The $z$ coordinates were determined by measuring the distance from the measurement point on the root system to the ground along a plumb line, using the ground surface as the origin. The root diameter was measured vertically and horizontally using a digital caliper and averaged. The number of measured root data points was 1791 for root system 1 and 1990 for root system 2 .

\subsection{Reconstruction of RSA from Root Point Data}

The root point data set, either calculated from the point cloud data or measured manually, was used to reconstruct the RSA (Figures 3 and 4). Pairs of adjacent points were connected to the approximate frustum of the cones. neuTube was used to analyze the connecting root point data and to display the roots. Since neuTube can import morphological models based on the SWC file format [39], we saved both scanner and manual measurement data in SWC format. The SWC format can allow the creation of MTG coding files, which are often used to study the relationship between RSA and anchorage [40].

\subsection{Calibration of RSA Data}

RSA data were acquired as pixels. We selected 10 identifiable key points (root end points and inflection points) in each root system (Figure S2), compared their $x y z$ coordinates and diameters between the 3D laser scanner data (in pixels) and the manual measurements (in $\mathrm{mm}$ ), and derived a formula to convert scanner data to $\mathrm{mm}$ (Table S1).

\subsection{Comparison of RSA Data Obtained by Different Methods}

To evaluate the differences in RSA data at the root point level between the methods, we compared the $x y z$ coordinates and root diameters at another 10 points in each root system (Figure 5). The differences (Di) in distances from each coordinate obtained by the manual measurement to that of the 3D laser scanner were calculated at the 10 root points in each root system. The accuracy (Ac) of root diameter at the 10 root points in each root system was defined as the percentage of the diameter estimated by the 3D laser scanner to that of the manual measurement according to Lau et al. [27]. To evaluate the differences across all RSA data in each root system, we compared the top and side views of the point cloud data with the RSA data reconstructed from the laser scanner data, and the latter with the manual measurements. 


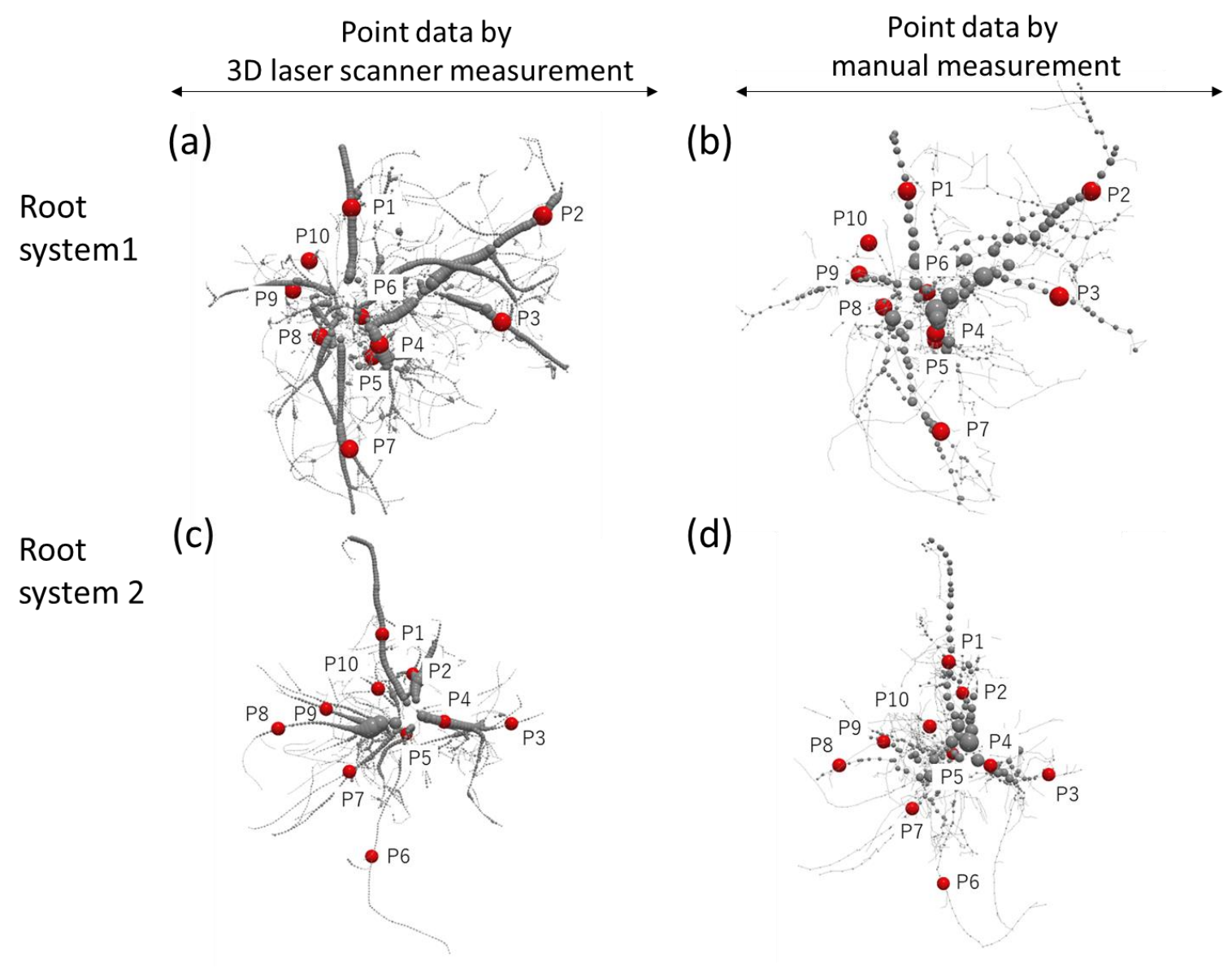

Figure 5. Positions of 10 points (P1-P10) set to evaluate the accuracy of the $x y z$ coordinates and root diameters in root point data collected in $(\mathbf{a}, \mathbf{b})$ Root system 1 and $(\mathbf{c}, \mathbf{d})$ Root system 2 by $(\mathbf{a}, \mathbf{c})$ 3D laser scanner and $(\mathbf{b}, \mathbf{d})$ hand.

We compared the change in root diameter (degree of root taper) in the direction of root extension between the measurement methods. We selected 10 main root segments in each reconstructed RSA (Figure 6) and compared the diameters between the methods. The accuracy (Ac) of the diameter in each root segment was defined as shown above. We also compared the differences between the methods in total root CSA in the vertical direction at a given horizontal distance from the collar center in the reconstructed RSAs. To approximate the root-soil plate as an elliptical pillar or a cylinder, it was necessary to measure the number, diameter, and CSA of the roots on the side of the cylinder (the root-soil plate). The total root CSA of the reconstructed RSA was calculated from the crosssectional diameter at concentric columnar surfaces every $100 \mathrm{~mm}$ (between $300 \mathrm{~mm}$ and $1800 \mathrm{~mm}$ ) from the collar center. The accuracy (Ac) of CSA was defined as the percentage of CSA by the 3D laser scanner to that of the manual measurement in each root system. 


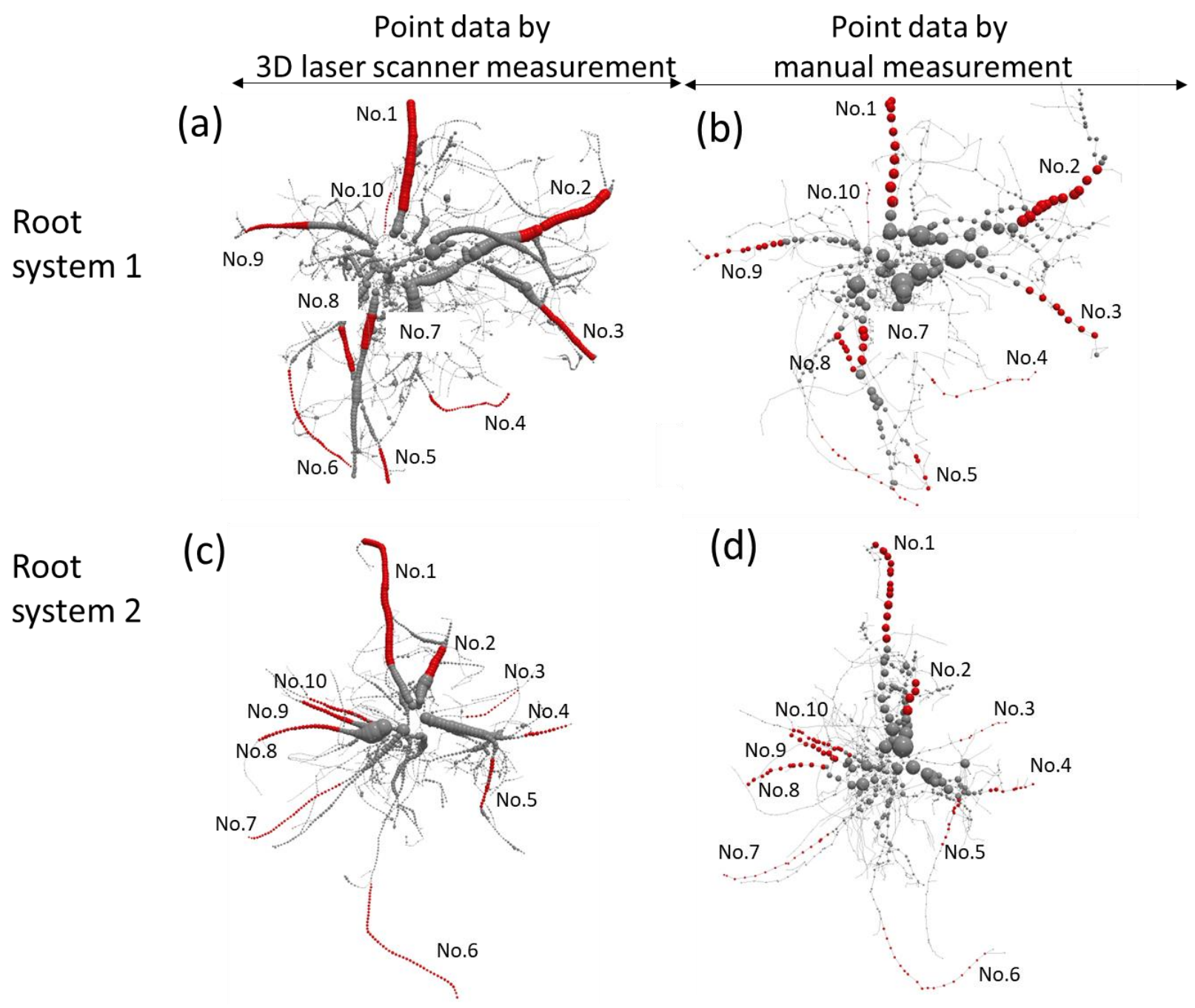

Figure 6. Ten main root segments in each root system selected to compare tapering between (a,b) in Root system 1; and (c,d) in Root system 2 measured by $(\mathbf{a}, \mathbf{c}) 3 \mathrm{D}$ scanner and $(\mathbf{b}, \mathbf{d})$ hand.

\subsection{Statistical Analysis}

Normal distribution of $x y z$ coordinates and diameters of 10 selected root point data, the diameters of 10 root segments along the long axis data, and total root CSA data in each root system was confirmed by the Kolmogorov-Smirnov test. We conducted a paired $t$-test to compare the differences in the diameters of the 10 root segments along the long axis data obtained by the manual measurement with those measurements obtained by the 3D laser scanner. We produced correlations between the manual and 3D laser scanner measurements in $x y z$ coordinates and the diameter of 10 selected root point data, and total CSA data. Because of the small sample size for each trait, we calculated bootstrapped estimates of the correlation coefficient for 1000 iterations and showed the values in the results. Statistical analyses were conducted using the R software version 4.0.2 [41].

\section{Results}

\subsection{Reconstruction of RSA in Manual and 3D Laser Scanner Measurements}

We successfully reconstructed the RSAs of the two $P$. thunbergii trees using neuTube software (Figures 3 and 4). Visually, the views from the top (Figure 3B,C and Figure 4B,C) and side (Figure $3 b, c$ and Figure $4 b, c$ ) of the 3D laser scanner RSAs, which were very similar to those of the point clouds (Figure 3A,a and Figure 4A,a; Figures S3a,b and S4a,b), 
and the main root segments were reproduced. However, the reconstructed RSAs were more sparse and were simpler than point clouds.

The manual data RSAs (Figure 3D,E,d,e and Figure $4 \mathrm{D}, \mathrm{E}, \mathrm{d}, \mathrm{e}$ ) were reconstructed to a similar extent as in the 3D laser scanner RSAs (Figure 3B,C,b,c and Figure 4B,C,b,c) based on visual comparison. Similarly, the main root segments were well reproduced. However, the manual data RSAs were simpler and sparser than the surface-shaped 3D laser scanner RSAs (Figure 3A, a and Figure 4A,a).

\subsection{Comparison of Root Point Data between Manual and 3D Laser Scanner Measurements}

The positions and root diameters at the 10 points in the root point data were positively correlated with the 3D laser scanner and the manual measurements in root systems 1 and $2(p<0.01$; Figure 7). The differences (Di) in the distance of $x, y$, and $z$ coordinates were $-1.4,-7.7$, and $-19.0 \mathrm{~mm}$ in root system 1 and $-45.7,20.5$, and $-7.7 \mathrm{~mm}$ in root system 2, respectively (Figure 7a-c). Roots with a diameter of approximately 7 to $50 \mathrm{~mm}$ were measured accurately in the root point data converted from the 3D laser scanner data (Figure $7 \mathrm{~d}$ ). The accuracies (Ac) of the diameters were $97.7 \%$ and $86.6 \%$ in root systems 1 and 2 , respectively.

(a) $x$ coordinate

\section{Root system 1}

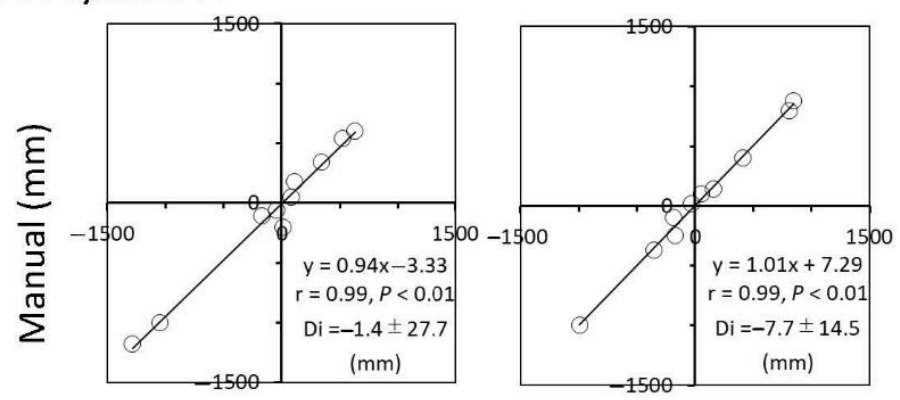

(b) $y$ coordinate

(c) $z$ coordinate
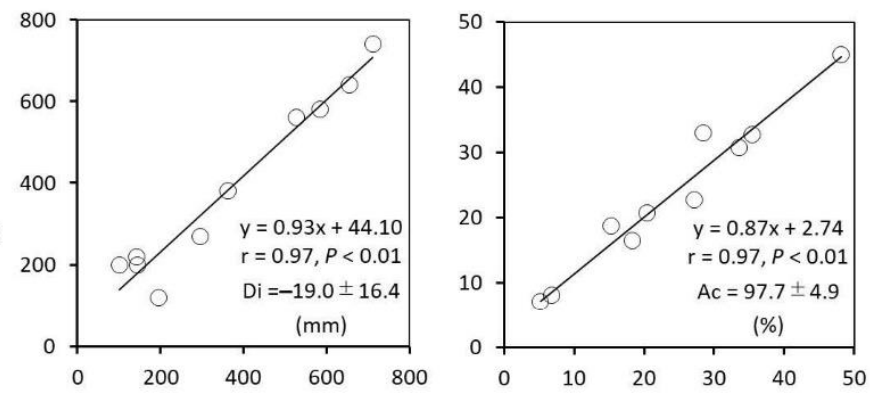

Root system 2
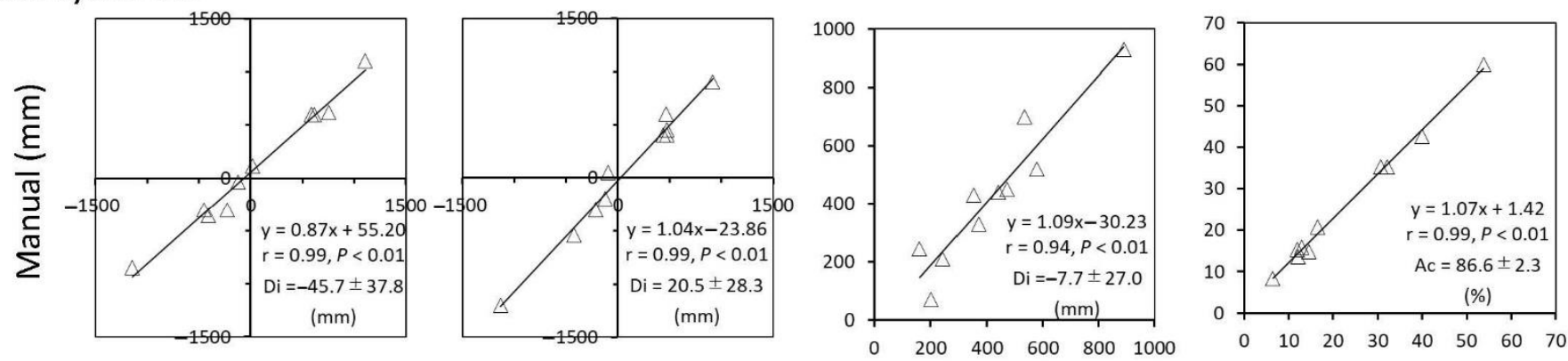

3D laser scanner $(\mathrm{mm})$

\section{(d) diameter}

Figure 7. Relationships of (a) $x,(\mathbf{b}) y,(\mathbf{c}) z$ coordinates, and (d) diameter of 10 selected root points between 3D laser scanner and manual measurements. The correlation coefficient (r) was calculated as the mean value estimated by 1000 bootstraps. The differences ( $\mathrm{Di}$, mean \pm standard error) in distances from each coordinate obtained by the manual measurement to that of the 3D laser scanner were calculated at the 10 root points in each root system. The accuracy (Ac, mean \pm standard error) of root diameter at 10 root points in each root system was defined as the percentage of the diameter estimated by the 3D laser scanner to that of the manual measurement according to Lau et al. [27].

\subsection{Differences in Taper and CSA of Roots between Manual and 3D Laser Scanner Measurements}

In a visual comparison, the taper trends of the 20 root segments in both root systems were similar between the 3D laser scanner and manual measurements, with variation (Figure 8 ). The mean difference in root diameter between the two measurement methods 
was $4.0 \mathrm{~mm}$, and the maximum was $16.4 \mathrm{~mm}$. The mean diameters of 14 of the 20 root segments estimated by manual measurement were not significantly different from the 3D laser scanner ( $p>0.05$; Figure 8$)$. Although the diameters of the remaining six root segments were significantly different between the measurements $(p<0.05$; Figure 8$)$, the differences were minimal $(-7.44$ and $7.94 \mathrm{~mm})$. The average accuracy $(\mathrm{Ac})$ of the 3D laser scanner measured diameter compared to the manually measured diameter of the root segment ranged between $80.1 \%$ to $117.0 \%$ for root system 1 and from $83.0 \%$ to $145.1 \%$ for root system 2, respectively (Figure 8).

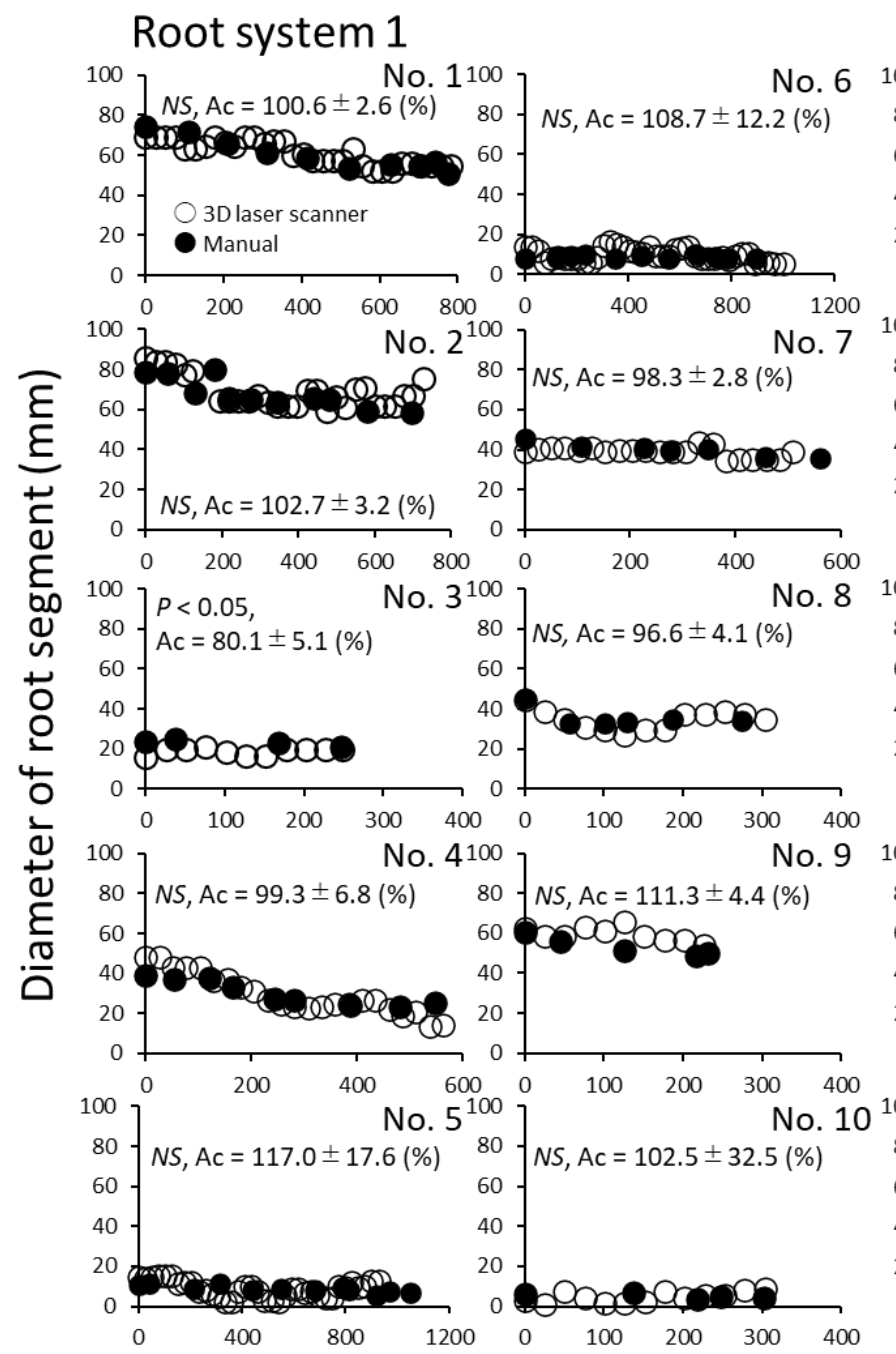

\section{Root system 2}
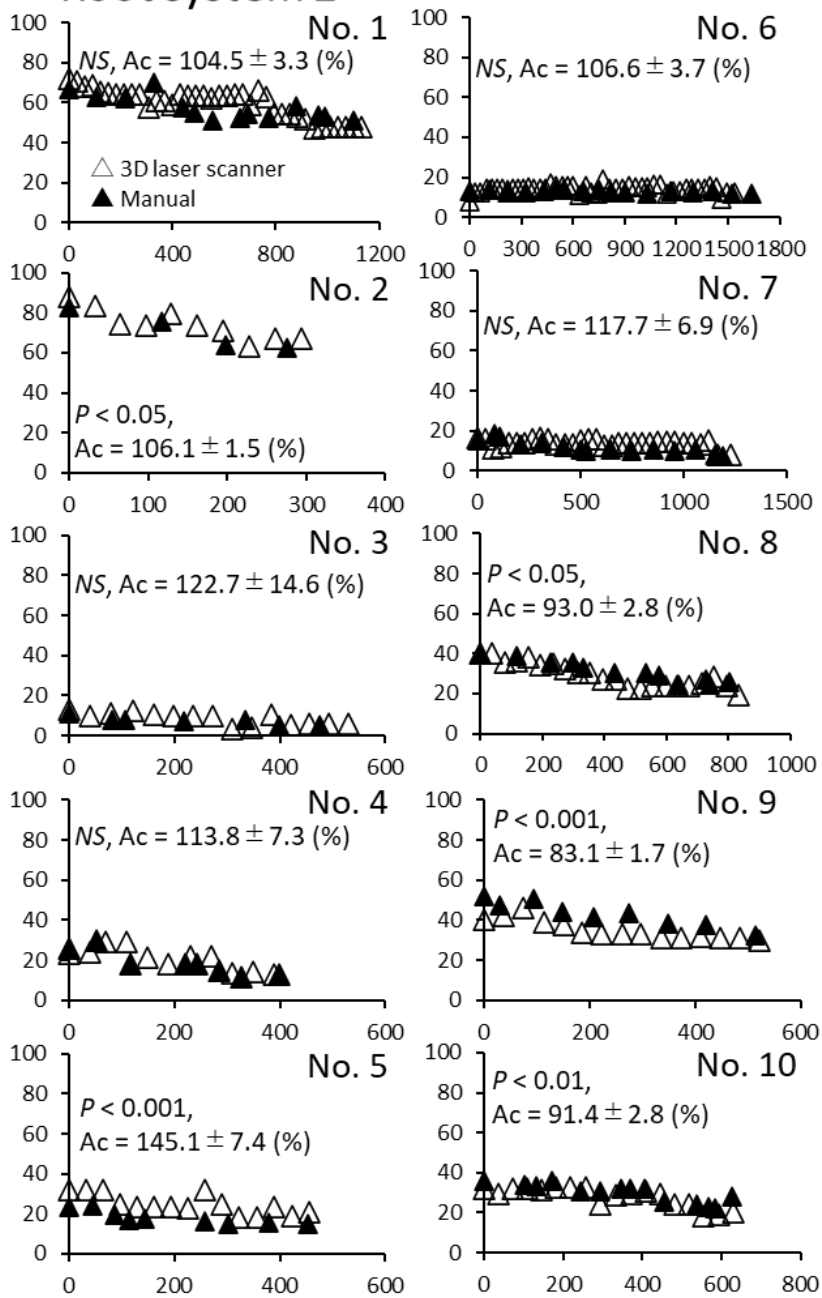

\section{Length of root segment along long axis $(\mathrm{mm})$}

Figure 8. Changes in the diameters of 10 root segments along the long axis in each root system by 3D laser scanner and manual measurements. A paired $t$-test was used to compare the differences in the diameters of 10 root segments along the long axis data obtained by the manual measurement with those obtained by the 3D laser scanner. NS: not significant $(p>0.05)$. The correlation coefficient ( $\mathrm{r}$ ) was calculated as the mean value estimated by 1000 bootstraps. The accuracy (Ac, mean \pm standard error) of the diameter at 10 root segments in each root system was defined as the percentage of the diameter estimated by the 3D laser scanner to that of the manual measurement according to Lau et al. [27].

The total CSAs tended to decrease with distance from the collar center in both methods (Figure 9a,b), notably so in root system 1 at $<500 \mathrm{~mm}$. The correlations of the total CSAs between the measurements were consistently high in each root system (root system 1 , $\mathrm{r}=0.90$; root system $2, \mathrm{r}=0.93$; Figure $9 \mathrm{a}, \mathrm{b})$. The accuracy (Ac) of CSA was $103.0 \%$ in root system 1 and $95.7 \%$ in root system 2 . There was a positive correlation between the 
methods, with a slope of $0.82(r=0.88)$, as seen in Figure 9c. This indicated that the total CSAs estimated by the 3D laser scanner were smaller than those estimated from manual measurements.

(a)

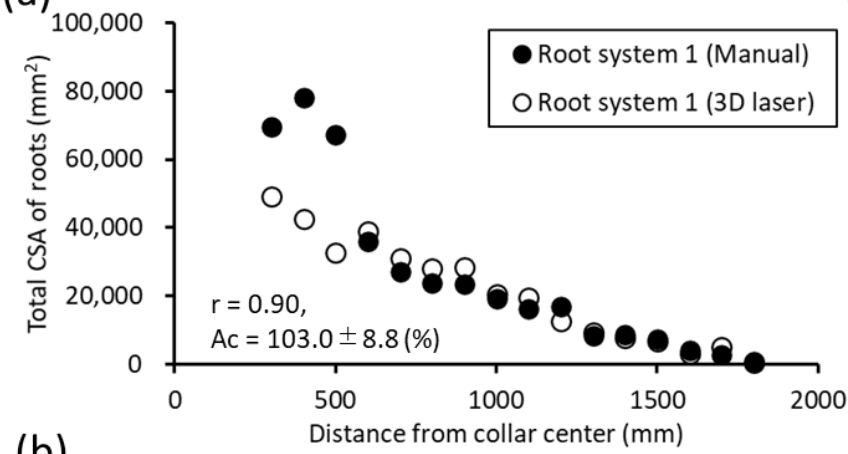

(b)

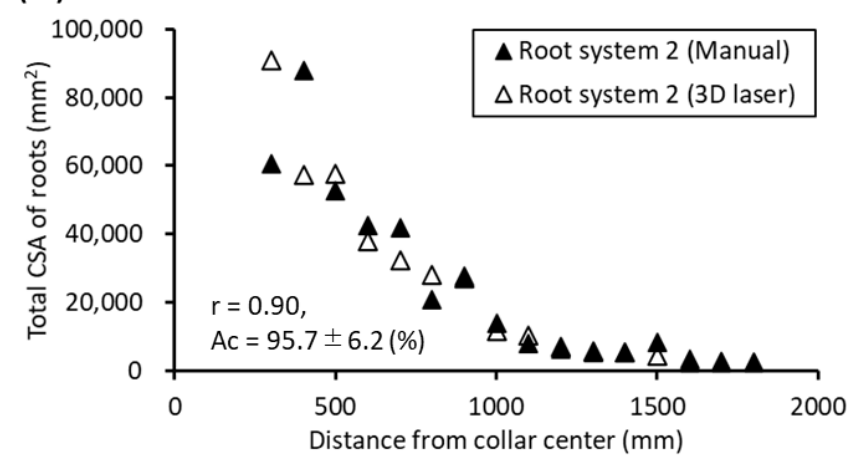

(c)

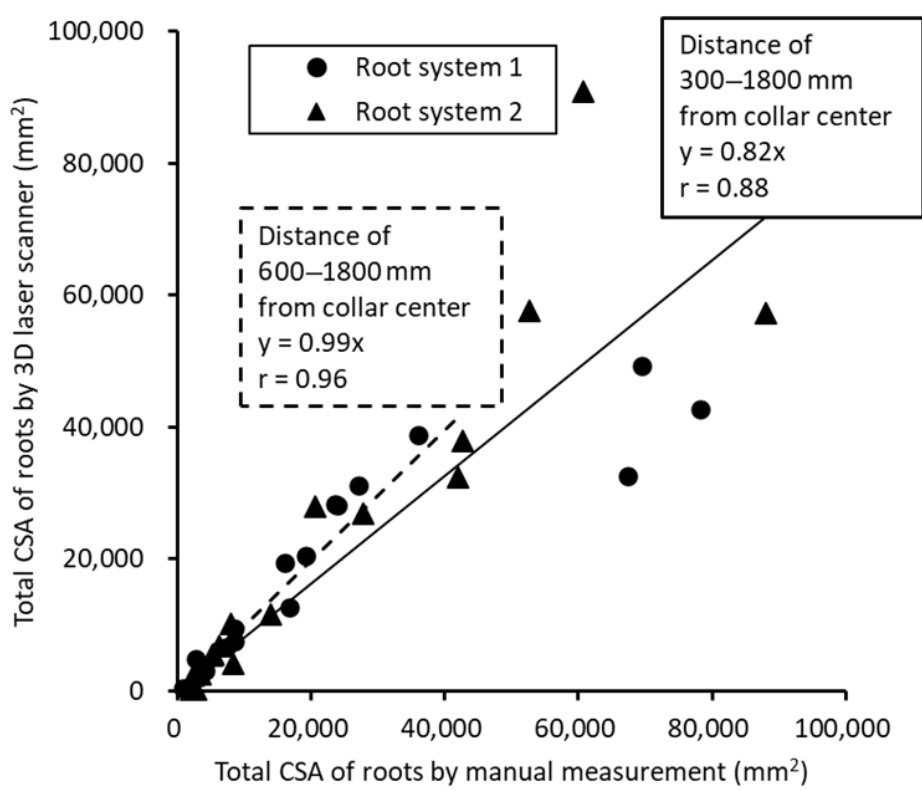

Figure 9. Total cross-sectional area (CSA) of (a) Root system 1 and (b) Root system 2 with distance from the collar center by 3D laser scanner and manual measurements. (c) Relationship of the total CSA of both root systems between 3D laser scanner and manual measurements. Paired t-test was used to compare the differences in the CSA at the distances from the collar center obtained by the manual measurement with those by the 3D laser scanner measurement. NS: not significant $(p>0.05)$. The correlation coefficient ( $\mathrm{r}$ ) was calculated as the mean value estimated by 1000 bootstraps. The accuracy (Ac, mean \pm standard error) of the CSA at the distances from the collar center in each root system was defined as the percentage of the CSA estimated by the 3D laser scanner to that of the manual measurement according to Lau et al. [27].

\section{Discussion}

\subsection{Significant Steps in Reconstructing RSA from Point Cloud Data}

We proposed an innovative method for reconstructing RSA and calculating traits such as taper and CSA of roots from root point data converted from point cloud data collected by a 3D laser scanner. This is the first application of the neuTube software, which was developed to reconstruct the neuronal structure [39], to the RSA of forest trees. The accuracy was very similar to that of the manually collected root point data. Although previous studies have scanned excavated root systems using a 3D laser scanner [28,31,42], the accuracy of the resultant root system models have not been evaluated against intensive manual measurements [31]. Moreover, one drawback of measuring RSA using a 3D laser scanner is that it is obtained as point cloud data [12].

Lau et al. [27] reported an absolute error of $5.14 \mathrm{~cm}$ in the diameter class of $10-20 \mathrm{~cm}$ of tree branches and $-3.46 \mathrm{~cm}$ in the $20-60 \mathrm{~cm}$ class when the data calculated by the QSM model using the point cloud data by the 3D laser scanner were compared with that of the manual measurement data. The accuracy (Ac) of the root diameter estimated by our proposed methods using the point cloud data of the 3D laser scanner measurement to the manually measured root diameter was $98 \%$ for root system 1 and $87 \%$ for root system 2 (Figure 7c). The difference in root diameter between the methods might have occurred due to the difference in the degree of dryness of the roots at the time of measurement. 
The maximum difference in distance (Di) between the coordinates of the roots was less than $46 \mathrm{~mm}$, and the minimum was $1.4 \mathrm{~mm}$ (Figure $7 \mathrm{a}-\mathrm{c}$ ). These results indicated that our proposed method, without any specific parameters, can be reproduced with high accuracy using a 3D laser scanner. Our proposed method can easily convert point cloud data to root point data and RSA data and calculate RSA traits. Such analysis is important for examining the resistance of trees to uprooting and landslides $[2,11,43]$. Information on root traits can only be obtained through the direct measurement of the root system. However, if the root point data or point cloud data are converted to RSA data, further details can be obtained from the stored data if required.

Another advantage of 3D laser scanner measurement is that it requires less labor and time to collect data where root systems were set either outside or inside the laboratory compared to manual and semi-automatic methods [12]. In this study, collecting $x y$ coordinates by hand at intervals of $10 \mathrm{~cm}$ and at the branches and tips of roots took three people and five days per root system. In contrast, 3D laser scanners set at eight points scanned the root system in $60 \mathrm{~min}$. By collecting a large number of data points, we can reconstruct subtle root irregularities and changes in root diameter that manual measurement would not reveal.

On the other hand, for the data treatment after the acquisition, 3D laser scanner measurement took one person $15 \mathrm{~h}$ per root system to eliminate noise from the point cloud data in 2014. However, the recent software for point cloud analysis has improved the performance and reduced the time required for noise elimination. Our process of converting the point cloud data of the root system into root point data was partly manual using ImageJ. It took about one person-hour to complete the conversion of the whole root system, and more than 2000 root point data were made. Thus, it took approximately 2.0 person-days to obtain the root point data from the point cloud data using a 3D laser scanner. The semi-automated method using 3D digitizing also took 2.5 person-days to obtain the whole root system in a 14-year P. pinaster with a DBH of 17.0-17.4 cm and the height of 9.7-10.9 $\mathrm{m}$ [6]. However, the method proposed in our study did not include the time for classifying segments in several root compartments, such as the ZRT. On the other hand, semi-automatic measurements provide the direction of ovality, which is required to compute flexural stiffness in a given direction of load [6]. Therefore, the 3D laser scanner method is inferior to the semi-automated method using 3D digitizing. If the time required for noise processing of point cloud data can be reduced and the work in ImageJ can be automated, further time reduction can be expected in the proposed method.

\subsection{Other Issues to Consider in the Use of 3D Laser Scanning}

There are some issues in the acquisition and analysis of point cloud data using 3D scanner measurements. First, when root systems are scanned, the positions of the excavated roots should be the same as that of the soil as much as possible, especially in the vertical direction. In our results, root system 1 and the $z$ coordinates, which indicate root depth, differed slightly between methods with the $x$ and $y$ coordinates (Figure 7). This may be because we scanned the root systems upright but measured them while upside down. Thin horizontal roots can be bolted to a plate [14] or tied to a stage or pole [28], but plenty of space is needed.

Second, the CSA of roots close to the collar, especially within $500 \mathrm{~mm}$, differed between methods (Figure 9), perhaps because the laser beam did not reach the whole root surface, owing to their proximity to each other and the collar. In fact, the slope of the relationship of CSA between the two methods was 0.99 at $600-1800 \mathrm{~mm}$ from the collar center $(\mathrm{r}=0.96$; Figure 9c), but was only 0.82 at 300-1800 mm, indicating that the CSA of roots near collars was larger by manual measurement than by 3D laser scanner measurement. The error can be reduced by: (i) taking a more detailed scan or using pointer lamps [28], where errors are likely to occur; and (ii) finding a location where the root diameter changes notably and then using a correction. 
Finally, a priority task is to tackle the problem of cross-sectional ovality, model the stump, and convert it into a file for RSA analysis (e.g., MTG file) to obtain a complete pipeline of measurements. neuTube assumes a circular cross-sectional shape; thus, each root segment is a frustum of a cone. This assumption is unsuitable for representing the heterogeneous shapes of root cross-sections, particularly for T- and I-shapes formed under intense stress [44]. Therefore, it is necessary to adapt this method to tree species with non-cylindrical roots. Furthermore, in this study, we did not collect point data from the stump, which is an important part of considering the whole root system and plays a specific role in anchorage [45].

Resolving these issues would allow for more accurate RSA data acquisition from 3D laser scanner measurements using our proposed method. As other reconstruction methods for modeling or branch architecture exist, comparison with these methods would be ideal to elucidate the advantages and disadvantages depending on the objective of the reconstruction [46].

The limitation of this study is that it focused on only one tree species of two Pinus thunbergii trees that had typical tap root systems. To establish it as a practical method, the estimated root traits in several tree species with different root system types and the advantages and disadvantages of the method during the measurement should be compared with the most common semi-automatic measurement methods [7].

\subsection{Future Aspects for RSA Measurement}

$3 \mathrm{D}$ measurement requires digging out the root system, so time-series data cannot be collected. Because root point data obtained by non-destructive methods, such as groundpenetrating radars [47], do not indicate connections, it is difficult to convert them into RSA data without a connection algorithm [48]. Recently, we devised a connection algorithm for point data of Cryptomeria japonica roots [13]. Such methods can be used to process root point data without connection information, but it is still necessary to excavate root systems and measure root positions, diameters, and connections manually before devising an algorithm [13]. Our results confirm that the root point data converted from the point cloud data and the reconstructed RSA are very similar to the manual data. Therefore, using 3D laser scanner data, we can develop connection algorithms for the root systems of other tree species.

\section{Conclusions}

We proposed a new method using the neuTube software to convert point cloud data to root point data to reconstruct the RSA of $P$. thunbergii. The RSAs proved to be accurate. The root point data were connected with frustum of the cones, and thus, the reconstructed RSAs were relatively simple but included the main coarse root segments. Although a 3D laser scanner can collect detailed data in a short time, it is expensive, the root system must be brought inside for measurement, and specific technology and time are required for imaging. In contrast, manual measurement requires intensive labor and time but does not require special machinery or technology. Semi-automatic measurements can address these challenges $[11,12,20]$. Essentially, RSA data can be obtained efficiently by 3D laser scanner analysis to evaluate the root anchorage and the slope stability of forest trees, provided that we could succeed in modeling both the stump and ovality of root sections.

Supplementary Materials: The following are available online at https:/ / www.mdpi.com/article/10 $.3390 / \mathrm{f} 12081117 / \mathrm{s} 1$, Table S1: Conversions of root point data from 3D laser scanner to scale based on the relationships in the coordinates or diameter of roots between manual measurement data (xm, $y m, z m, d m)$ and 3D laser scanner measurement data (x3D, y3D, z3D, d3D). Figure S1: How we measured the root system by hand against a $100 \mathrm{~mm} \times 100 \mathrm{~mm}$ grid. This photo shows Cryptomeria japonica. Figure S2: Positions of 10 points (K1-K10) set to relate the locations of roots to the actual scale. Figure S3: (a) Top and (b) side views of root system 1 drawn from point cloud data collected by the 3D laser scanner. These are the same as in Figure $3(\mathrm{~A}, \mathrm{a})$ but enlarged. Figure S4: (a) Top and (b) 
side views of root system 2 drawn from point cloud data collected by the 3D laser scanner. These are the same as in Figure $4(\mathrm{~A}, \mathrm{a})$ but enlarged.

Author Contributions: C.T.: planned and performed the experiments, analyzed the data, wrote the paper, and prepared it for submission; H.I.: planned and performed the experiments, analyzed the data, and wrote the paper; K.Y., T.T., and M.D.: performed the experiments and analyzed the data; M.O. and T.K.: analyzed the data; Y.H.: planned and performed the experiments, analyzed the data, and wrote and edited the paper. All authors have read and agreed to the published version of the manuscript.

Funding: This study was partly supported by JSPS KAKENHI grants (JP25252027 and 2003028).

Data Availability Statement: Data available in a publicly accessible repository that does not issue DOIs. Publicly available datasets were analyzed in this study. These data can be found at https: / / github.com/Hidetoshilkeno/3D-RSA (accessed on 14 July 2021).

Acknowledgments: We appreciate the editor and reviewers for providing constructive comments and suggestions for the enhancement of our manuscript. We thank Y. Kimura, Y. Nakagawa, T. Akamatsu, A. Takamatsu, and M. Yoshida (University of Hyogo) for collecting the data manually; $\mathrm{H}$. Ogata, H. Nakamura (woodinfo Co., Ltd.) for the 3D scanning, and J. Tanaka (Japan Conservation Engineers \& Co., Ltd.) and Aichi Prefecture for allowing us to conduct the experiment at the study site.

Conflicts of Interest: The authors declare that they have no conflict of interest.

\section{References}

1. Jackson, R.B.; Pockman, W.T.; Hoffmann, W.A. The Structure and Function of Root Systems. In Handbook of Functional Plant Ecology; Pugnaire, F.I., Valladares, F., Eds.; Marcel Dekker, Inc.: New York, NY, USA, 1999; pp. 196-220.

2. Schwarz, M.; Lehmann, P.; Or, D. Quantifying Lateral Root Reinforcement in Steep Slopes-From a Bundle of Roots to Tree Stands. Earth Surf. Process Landf. 2010, 35, 354-367. [CrossRef]

3. Yamase, K.; Todo, C.; Torii, N.; Tanikawa, T.; Yamamoto, T.; Ikeno, H.; Ohashi, M.; Dannoura, M.; Hirano, Y. Dynamics of Soil Reinforcement by Roots in a Regenerating Coppice Stand of Quercus serrata and Effects on Slope Stability. Ecol. Eng. 2021, 162, 106169. [CrossRef]

4. Ennos, A.R. The Mechanics of Root Anchorage. Adv. Bot. Res. 2000, 33, 133-157.

5. Ghestem, M.; Veylon, G.; Bernard, A.; Vanel, Q.; Stokes, A. Influence of Plant Root System Morphology and Architectural Traits on Soil Shear Resistance. Plant Soil 2014, 377, 43-61. [CrossRef]

6. Dorval, A.D.; Meredieu, C.; Danjon, F. Anchorage Failure of Young Trees in Sandy Soils Is Prevented by a Rigid Central Part of the Root System with Various Designs. Ann. Bot. 2016, 18, 747-762. [CrossRef] [PubMed]

7. Danjon, F.; Stokes, A.; Bakker, M.R. Root Systems of Woody Plants. In Plant Roots; The Hidden Half; CRC Press: Boca Raton, FL, USA, 2013; p. 848.

8. Yang, M.; Défossez, P.; Danjon, F.; Fourcaud, T. Analyzing Key Factors of Roots and Soil Contributing to Tree Anchorage of Pinus species. Trees 2018, 32, 703-712. [CrossRef]

9. Liang, T.; Knappett, J.A.; Bengough, A.G.; Ke, Y.X. Small-Scale Modelling of Plant Root Systems Using 3D Printing, with Applications to Investigate the Role of Vegetation on Earthquake-Induced Landslides. Landslides 2017, 14, 1747-1765. [CrossRef]

10. Yamase, K.; Tanikawa, T.; Dannoura, M.; Todo, C.; Yamamoto, T.; Ikeno, H.; Ohashi, M.; Aono, K.; Doi, R.; Hirano, Y. Estimating Slope Stability by Lateral Root Reinforcement in Thinned and Unthinned Stands of Cryptomeria japonica Using Ground-Penetrating Radar. Catena 2019, 183, 104227. [CrossRef]

11. Danjon, F.; Fourcaud, T.; Bert, D. Root Architecture and Wind-Firmness of Mature Pinus pinaster. New Phytol. 2005, 168, 387-400. [CrossRef]

12. Danjon, F.; Reubens, B. Assessing and Analyzing 3D Architecture of Woody Root Systems, a Review of Methods and Applications in Tree and Soil Stability, Resource Acquisition and Allocation. Plant Soil 2008, 303. [CrossRef]

13. Ohashi, M.; Ikeno, H.; Sekihara, K.; Tanikawa, T.; Dannoura, M.; Yamase, K.; Todo, C.; Tomita, T.; Hirano, Y. Reconstruction of Root Systems in Cryptomeria japonica Using Root Point Coordinates and Diameters. Planta 2019, 249, 445-455. [CrossRef]

14. Henderson, R.; Ford, E.D.; Renshaw, E.; Deans, J.D. Morphology of the Structural Root System of Sitka spruce 1. Analysis and Quantitative Description. Forestry 1983, 56, 121-135.

15. Mulatya, J.M.; Wilson, J.; Ong, C.K.; Deans, J.D.; Sprent, J.I. Sprent. Agrofor. Syst. 2002, 56, 65-72. [CrossRef]

16. Oppelt, A.L.; Kurth, W.; Dzierzon, H.; Jentschke, G.; Godbold, D.L. Structure and Fractal Dimensions of Root Systems of Four Co-Occurring Fruit Tree Species from Botswana. Ann. For. Sci. 2000, 57, 463-475. [CrossRef]

17. Godin, C.; Caraglio, Y.; Costes, E. Exploring Plant Topological Structure with the AMAPmod Software: An Outline. Silva Fenn. 1997, 31, 357-368. [CrossRef] 
18. Danjon, F.; Sinoquet, H.; Godin, C.; Colin, F.; Drexhage, M. Characterisation of Structural Tree Root Architecture Using 3D Digitising and AMAPmod Software. Plant Soil 1999, 211, 241-258. [CrossRef]

19. Sorgonà, A.; Proto, A.R.; Abenavoli, L.M.; Di Iorio, A. Spatial Distribution of Coarse Root Biomass and Carbon in a High-Density Olive Orchard: Effects of Mechanical Harvesting Methods. Trees 2018, 32, 919-931. [CrossRef]

20. Cast, C.S.; Meredieu, C.; Défossez, P.; Pagès, L.; Danjon, F. Modelling Root System Development for Anchorage of Forest Trees up to the Mature Stage, Including Acclimation to Soil Constraints: The Case of Pinus pinaster. Plant Soil 2019, 439, 405-430. [CrossRef]

21. Lontoc-Roy, M.; Dutilleul, P.; Prasher, S.O.; Han, L.; Smith, D.L. Computed Tomography Scanning for Three-Dimensional Imaging and Complexity Analysis of Developing Root Systems. Can. J. Bot. 2005, 83, 1434-1442. [CrossRef]

22. Calders, K.; Newnham, G.; Burt, A.; Murphy, S.; Raumonen, P.; Herold, M.; Culvenor, D.; Avitabile, V.; Disney, M.; Armston, J.; et al. Nondestructive Estimates of Above-Ground Biomass Using Terrestrial Laser Scanning. Methods Ecol. Evol. 2015, 6, 198-208. [CrossRef]

23. Dassot, M.; Constant, T.; Fournier, M. The Use of Terrestrial LiDAR Technology in Forest Science: Application Fields, Benefits and Challenges. Ann. For. Sci. 2011, 68, 959-974. [CrossRef]

24. Raumonen, P.; Kaasalainen, M.; Åkerblom, M.; Kaasalainen, S.; Kaartinen, H.; Vastaranta, M.; Holopainen, M.; Disney, M.; Lewis, P. Fast Automatic Precision Tree Models from Terrestrial Laser Scanner Data. Remote Sens. 2013, 5, 491-520. [CrossRef]

25. Seidel, D.; Fleck, S.; Leuschner, C.; Hammett, T. Review of Ground-based Methods to Measure the Distribution of Biomass in Forest Canopies. Ann. For. Sci. 2011, 68, 225-244. [CrossRef]

26. Srinivasan, S.; Popescu, S.; Eriksson, M.; Sheridan, R.; Ku, N. Terrestrial Laser Scanning as an Effective Tool to Retrieve Tree Level Height, Crown Width, and Stem Diameter. Remote Sens. 2015, 7, 1877-1896. [CrossRef]

27. Lau, A.; Bentley, L.P.; Martius, C.; Shenkin, A.; Bartholomeus, H.; Raumonen, P.; Malhi, Y.; Jackson, T.; Herold, M. Quantifying Branch Architecture of Tropical Trees Using Terrestrial LiDAR and 3D Modelling. Trees 2018, 32, 1219-1231. [CrossRef]

28. Gärtner, H.; Wagner, B.; Heinrich, I.; Denier, C. 3D-Laser Scanning: A New Method to Analyze Coarse Tree Root Systems. For. Snow Landsc. Res. 2009, 82, 95-106.

29. Wagner, B.; Gärtner, H.; Ingensand, H.; Santini, S. Incorporating 2D tree-ring data in 3D laser scans of coarse-root systems. Plant Soil 2010, 334, 175-187. [CrossRef]

30. Wagner, B.; Santini, S.; Ingensand, H.; Gärtner, H. A tool to model 3D coarse-root development with annual resolution. Plant Soil 2011, 346, 79-96. [CrossRef]

31. Smith, A.; Astrup, R.; Raumonen, P.; Liski, J.; Krooks, A.; Kaasalainen, S.; Åkerblom, M.; Kaasalainen, M. Tree Root System Characterization and Volume Estimation by Terrestrial Laser Scanning and Quantitative Structure Modeling. Forests 2014, 5, 3274-3294. [CrossRef]

32. Sakamoto, T.; Noguchi, H.; Gotoh, Y.; Suzuki, S.; Shimada, K. Management of Japanese Black Pine (Pinus thunbergii) Seedlings Caused by Natural Regeneration. J. Jpn. Soc. Coast. For. 2013, 12, 29-34, (In Japanese with English summary)

33. Tanaka, J.; Nakazawa, H.; Satou, T. Case Study of Root Systems Growth of Pinus thunbergii Parlatore and Groundwater Level in the Nishinohama Coastal Forest, Tahara City, Aichi Prefecture. J. JSRT 2017, 43, 298-301. (In Japanese) [CrossRef]

34. Hirano, Y.; Todo, C.; Yamase, K.; Tanikawa, T.; Dannoura, M.; Ohashi, M.; Doi, R.; Wada, R.; Ikeno, H. Quantification of the Contrasting Root Systems of Pinus thunbergii in Soils with Different Groundwater Levels in a Coastal Forest in Japan. Plant Soil 2018, 426, 327-337. [CrossRef]

35. Todo, C.; Tokoro, C.; Yamase, K.; Tanikawa, T.; Ohashi, M.; Ikeno, H.; Dannoura, M.; Miyatani, K.; Doi, R.; Hirano, Y. Stability of Pinus thunbergii Between Two Contrasting Stands at Differing Distances from the Coastline. For. Ecol. Manag. 2019, 431, 44-53. [CrossRef]

36. FAO-UNESCO. Soil Map of the World. Revised Legend. Reprinted with Corrections. In World Soil Resources Report 60; Food and Agriculture Organization: Rome, Italy, 1990; p. 119.

37. Japan Meteorological Agency. Available online: http://www.data.jma.go.jp/obd/stats/etrn/ (accessed on 18 April 2021).

38. FARO Technologies Inc. FARO Laser Scanner Focus. Available online: https://faro.app.box.com/s/kfpwjofogeegocr7mf2s866s2 qalnaqw (accessed on 18 April 2021).

39. Feng, L.; Zhao, T.; Kim, J. neuTube 1.0: A New Design for Efficient Neuron Reconstruction Software Based on the Swc Format. eNeuro 2015, 2. [CrossRef] [PubMed]

40. Yang, M.; Defossez, P.; Dupont, S. A Root-to-Foliage Tree Dynamic Model for Gusty Winds During Wind Storm Conditions. Agric. Meteorol. 2020, 287, 107949. [CrossRef]

41. R Core Team. R: A Language and Environment for Statistical Computing; R Foundation for Statistical Computing: Vienna, Austria, 2017; Available online: https:/ / www.R-project.org/ (accessed on 12 July 2020).

42. Liski, J.; Kaasalainen, S.; Raumonen, P.; Akujärvi, A.; Krooks, A.; Repo, A.; Kaasalainen, M. Indirect Emissions of Forest Bioenergy: Detailed Modeling of Stump-Root Systems. GCB Bioenergy 2014, 6, 777-784. [CrossRef]

43. Coutts, M.P. Components of Tree Stability in Sitka Spruce on Peaty Gley Soil. Forestry 1986, 59, 173-197. [CrossRef]

44. Nicoll, B.C.; Ray, D. Adaptive Growth of Tree Root Systems in Response to Wind Action and Site Conditions. Tree Physiol. 1996, 16, 891-898. [CrossRef] [PubMed]

45. Nicoll, B.C.; Easton, E.P.; Milner, A.D.; Walker, C.; Coutts, M.P. Wind Stability Factors in Tree Selection: Distribution of Biomass within Root Systems of Sitka Spruce Clones. In Wind and Trees; Coutts, M.P., Grace, J., Eds.; Cambridge University Press: Cambridge, UK, 1995; pp. 276-292. 
46. Boudon, F.; Preuksakarn, C.; Ferraro, P.; Diener, J.; Nacry, P.; Nikinmaa, E.; Godin, C. Quantitative Assessment of Automatic Reconstructions of Branching Systems Obtained from Laser Scanning. Ann. Bot. 2014, 114, 853-862. [CrossRef]

47. Hirano, Y.; Yamamoto, R.; Dannoura, M.; Aono, K.; Igarashi, T.; Ishii, M.; Yamase, K.; Makita, N.; Kanazawa, Y. Detection Frequency of Pinus thunbergii Roots by Ground-Penetrating Radar Is Related to Root Biomass. Plant Soil 2012, 360, $363-373$. [CrossRef]

48. Kaestner, A.; Schneebeli, M.; Graf, F. Visualizing Three-Dimensional Root Networks Using Computed Tomography. Geoderma 2006, 136, 459-469. [CrossRef] 